\section{Commentary: Elevated atrial temperature in robotic assisted mitral valve surgery: Is it significant?}

\author{
Nkosi H. Alvarez, MD, ${ }^{\mathrm{a}}$ and \\ T. Sloane Guy, MD, MBA ${ }^{\mathrm{b}}$
}

Momin and colleagues ${ }^{1}$ report on the atrial temperature differences in patients undergoing open and robotic isolated mitral valve repair with single-shot antegrade del Nido cardioplegia. With a noncontact infrared thermometer, Momin and colleagues ${ }^{1}$ demonstrated that in the body of the right atrium (RA), temperatures at the end of cardioplegia administration and up to 20 minutes after aortic crossclamp were significantly lower in open mitral valve surgery than in robotic mitral valve surgery. Moreover, Momin and colleagues ${ }^{1}$ established that there was no difference in RA body temperature between open and robotic surgery 30 minutes after cardioplegia administration until cross clamp removal.

Although Momin and colleagues ${ }^{1}$ are to be commended for their findings, there remains the central question of clinical significance of the results. They found that temperatures in the RA were higher during robotic surgery than in open surgery at 3 defined intraoperative time points, with implications for potential myocardial compromise. Robotic mitral valve surgery, however, is associated with a high likelihood of valve repair and low operative mortality and morbidity, ${ }^{2,3}$ with postoperative outcomes that are similar or better than those obtained with conventional open sternotomy. ${ }^{3,4}$ Further investigation would be necessary to tell whether the differences in RA hypothermic temperature

From the ${ }^{\mathrm{a}}$ Department of Surgery and ${ }^{\mathrm{b}}$ Division of Cardiovascular Surgery, Thomas Jefferson University Hospital, Philadelphia, $\mathrm{Pa}$.

There were no external funding sources and no author had any conflicts of interest.

Disclosures: Dr Guy discloses a financial relationship with Edwards Lifesciences, Medtronic, Verb Surgical, and Intuitive Surgical. Dr Alvarez has nothing to disclose with regard to commercial support.

Received for publication Dec 1, 2019; revisions received Dec 1, 2019; accepted for publication Dec 3, 2019; available ahead of print Jan 31, 2020.

Address for reprints: T. Sloane Guy, MD, MBA, Division of Cardiovascular Surgery, Thomas Jefferson University, 1015 Walnut St, Curtis Building, Suite 620, Philadelphia, PA 19107 (E-mail: sloane.guy@jefferson.edu).

JTCVS Techniques 2020;1:44-5

2666-2507

Copyright (C) 2020 The Author(s). Published by Elsevier Inc. on behalf of The American Association for Thoracic Surgery. This is an open access article under the CC BY-NC-ND license (http://creativecommons.org/licenses/by-nc-nd/4.0/).

https://doi.org/10.1016/j.xjtc.2019.12.006

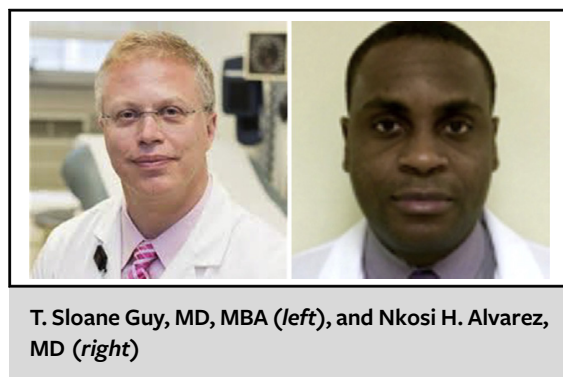

CENTRAL MESSAGE

Elevated right atrial temperatures found in robotic mitral value surgery may or may not be clinically significant or reflect ventricular myocardial temperatures.

between the procedures correlate with increased myocardial oxygen consumption that is deleterious enough to produce clinically significant myocardial outcomes.

In their examination of myocardial temperature, Momin and colleagues ${ }^{1}$ measured the temperature from the RA body directly with a contactless infrared probe. RA temperature has not been proved to be an accurate surrogate for ventricular myocardial temperature, however, which traditionally has been measured via myocardial septal temperatures. ${ }^{5}$ The closed thoracic space in robotic surgery mitral procedures likely contributes to the increased RA body temperatures (less heat dissipation, radiant heat from camera light source), but it is unclear whether the temperature in the body of the RA within the operative field would reflect the temperature of the left ventricular muscle. Septal temperature measurements could in fact be easily measured during robotic surgery by placing a standard temperature probe into the ventricular septum, and this perhaps should be considered in future studies.

The findings nonetheless do provoke questions about the need to investigate further myocardial temperature during robotic cardiac surgery. One solution to the warming effect might be to apply cold crystalloid to the heart intermittently with the robotic suction irrigator to reduce myocardial temperature. In our program, we have not found that to be necessary, although we have found that the routine use of intermittent retrograde cardioplegia after the initiation of antegrade cardioplegia and redosing at an hour (half dose) may also facilitate improved myocardial protection. Nonetheless, because of increasing amounts of minimally 
invasive and robotic mitral valve surgery being performed, the need to further our understanding of the clinical significance of increased RA myocardial temperature and techniques to negate these effects is vital, and this area should be thoroughly explored.

\section{References}

1. Momin AA, Chemtob RA, Lopez DC, Gillinov AM, Wierup P, Mick SL. Open sternum, cooler heart: the effect of surgical approach on myocardial temperature. J Thorac Cardiovasc Surg Tech. 2020;1:41-2.
2. Gillinov AM, Mihaljevic T, Javadikasgari H, Suri RM, Mick SL, Navia JL, et al Early results of robotically assisted mitral valve surgery: analysis of the first 1000 cases. J Thorac Cardiovasc Surg. 2018;155:82-91.e2.

3. Suri RM, Antiel RM, Burkhart HM, Huebner M, Li Z, Eton DT, et al. Quality of life after early mitral valve repair using conventional and robotic approaches. Ann Thorac Surg. 2012;93:761-9.

4. Chitwood WR Jr, Rodriguez E, Chu MW, Hassan A, Ferguson TB, Vos PW, et al Robotic mitral valve repairs in 300 patients: a single-center experience. J Thorac Cardiovasc Surg. 2008;136:436-41.

5. Dearani JA, Axford TC, Patel MA, Healey NA, Lavin PT, Khuri SF. Role of myocardial temperature measurement in monitoring the adequacy of myocardial protection during cardiac surgery. Ann Thorac Surg. 2001;72:S2235-43; discussion S2243-4, S2267-70. 